\title{
A STUDY OF SPIRITUAL INTELLIGENCE OF HIGHER SECONDARY SCHOOL STUDENTS IN CONTEXT OF AREA
}

\author{
Prof. Dr. Veenaben K. Patel \\ Mr. Ajay B. Raval
}

\begin{abstract}
Spiritual Intelligence is concerned with the inner life of mind and spirit and its relationship to being in the world. SI implies a capacity for a deep understanding of existential questions and insight into multiple levels of consciousness. Objective: 1) To determine the level of SI in the students. 2) To find out the effect of Area on SI of the students. Research Area for study is Educational Psychology. The students studying in Standard-11 in Gujarati Medium Schools of Gandhinagar became the population of the study. Selection of school was by Stratified Random Technique and selection of students was by cluster method. Sample size was of 423 students. "Survey Method" was selected for study. Self Constructed SI Scale was used for Data Collection. t-test was applied and $P_{33}$ and $P_{67}$ was used to determine the level. 1) According to Level of SI, 33.57\% Students are in Low and Medium Level and 32.86\% Students are in High Level. 2) In Low and Medium Level of SI, percentage of Students of rural area students is more than urban area and in high Level it is vice versa. 3) In matter of SI students of rural and urban area are equal.
\end{abstract}

Key-Words: Spiritual Intelligence (SI), Area, Higher Secondary School, Gandhinagar 
Towards Excellence: An Indexed, Refereed \& Peer Reviewed Journal of Higher Education / Dr.

\section{Veenben Patel \& Mr. Ajay Raval / Page 175-182}

\section{Introduction}

Spiritual Intelligence is concerned with the inner life of mind and spirit and its relationship to being in the world. Spiritual Intelligence (SI)implies a capacity for a deep understanding of existential questions and insight into multiple levels of consciousness. Spiritual Intelligence also implies awareness of spirit as the ground of being or as the creative life from stardust to mineral, vegetable, animal, and human existence implies some form of intelligence emerges as consciousness evolves into an ever-deepening awareness of matter, life, body, mind, soul and spirit. Spiritual Intelligence, then, is more than individual mental ability. At higher secondary level of schools, students have their enough capability to judge them self. Investigator has also witnessed that students of higher secondary school have ability to think.

\section{Review of related literature}

Abstract from past researches is presented here:

Garia, Hemalata has studied in 2005 the title was "A Study of Intellectual Ability, Emotional Intelligence and Spiritual Intelligence of Post Graduate students in relation to their Gender, Academic Attainments" the main findings were 1) boys and girls were equal in overall Emotional Intelligence.2) Students from arts stream were having more emotional intelligence concerned with handling their relationship than commerce stream. 3) Students from science stream were having more emotional intelligence concerned with recognizing emotions than arts stream. Chang (2007) studied that adolescence can be a time when teens attempt to reconcile their own desires and needs with the wishes of their parents.

\section{Statement of the problem}

For present study, Researcher decides to study Spiritual Intelligence of Higher Secondary School students in context Area. Thus title was as followed:

\section{A Study of Spiritual Intelligence of Higher Secondary School Students in context of Area}

\section{Importance of the study}

A research is a continuous process which is connected to a certain direction and therefore it is obvious for a researcher to keep in mind the importance of the study.

$>$ Teacher and Parents will get appropriate guidance to know Spiritual Intelligence of the higher secondary School students.

\section{Objectives}

The following objectives were determined for present study. 
Towards Excellence: An Indexed, Refereed \& Peer Reviewed Journal of Higher Education / Dr.

Veenben Patel \& Mr. Ajay Raval / Page 175-182

To determine the level of Spiritual Intelligence in the students.

$>$ To determine the level of Spiritual Intelligence in the students in context of Area.

To find out the effect of Area on Spiritual Intelligence of the students.

\section{Research Area}

Research in Education has so many research areas. In present study, researcher wants to study and assess the Spiritual Intelligence of the higher secondary school student. So, Research Area for present study is Educational Psychology.

\section{Hypotheses}

Following null hypotheses are formulated according to the study objectives:

$\mathrm{Ho}_{1}$ There will be no significant difference between the mean score of Spiritual Intelligence obtained by students of rural area and urban area.

\section{Limitation of the study}

The study was conducted considering the following limitations:

The limitation of sampling technique remains as a limitation of the study.

$>$ The findings was derived from the response of the respondents so that remains a limitation of the study

\section{Delimitation of the study}

Research is a broad and wide subject. Due to limitation of time, energy and money, he/she is delimiting the study.

Delimitation for the present study is as followed:

$>$ This study was delimited to the students of Standard-11 of Gujarati Medium Higher Secondary Schools of Gandhinagar District only.

\section{Definition of the key-words}

* Spiritual Intelligence:

\section{Theoretical Definition:}

Spiritual Intelligence is a term used by some Philosophers, Psychologists and developmental Theorists to indicate spiritual parallels with IQ (Intelligence Quotient) and EQ (Emotional Quotient). Spiritual Intelligence is a higher dimension of intelligence that activates the qualities and capabilities of soul, in the form of wisdom, compassion, integrity, joy, love, creativity, and peace, which results in a sense of deeper meaning and purpose combines with improvements in a wide range of important life skills and work skills. 
Towards Excellence: An Indexed, Refereed \& Peer Reviewed Journal of Higher Education / Dr.

\section{Veenben Patel \& Mr. Ajay Raval / Page 175-182}

- Richard Griffiths

\section{Operational Definition:}

In present study, scores obtain by the students on self-constructed Spiritual Intelligence Scale was considered as a Spiritual Intelligence of the students.

\section{Variables}

Following are the variables for the present study:

Independent Variable

\begin{tabular}{|c|c|c|}
\hline No. & Independent Variable & Level \\
\hline \multirow{2}{*}{1} & Area & Rural \\
\cline { 3 - 3 } & & Urban \\
\hline
\end{tabular}

Dependent Variable

In the present study, the Spiritual Intelligence of higher secondary school students is considered as the Dependent Variable.

\section{Controlled Variable}

District: Gandhinagar

Medium: Gujarati

Standard: 11

\section{Population and Sample}

The students studying in Standard-11 in Gujarati Medium Higher Secondary Schools of Gandhinagar District became the population of the present study. The list of all higher secondary school of Gandhinagar District was prepared. All schools were classified into general stream and science stream schools and after into rural and urban area. Schools were selected by Lottery Method. All students studying in selected schools were the sample of present study by cluster method. Thus, selection of school was by Stratified Random Technique and selection of students was by cluster sample method. At last, sample size was of 423 students.

Table: A

Sample

\begin{tabular}{|c|c|c|c|}
\hline Gender $>$ & Boy & Girl & Total \\
\cline { 1 - 2 } Area V & 117 & 87 & 204 \\
\hline Rural & & & \\
\hline
\end{tabular}


Towards Excellence: An Indexed, Refereed \& Peer Reviewed Journal of Higher Education / Dr.

Veenben Patel \& Mr. Ajay Raval / Page 175-182

\begin{tabular}{|c|c|c|c|}
\hline Urban & 115 & 104 & 219 \\
\hline Total & 232 & 191 & 423 \\
\hline
\end{tabular}

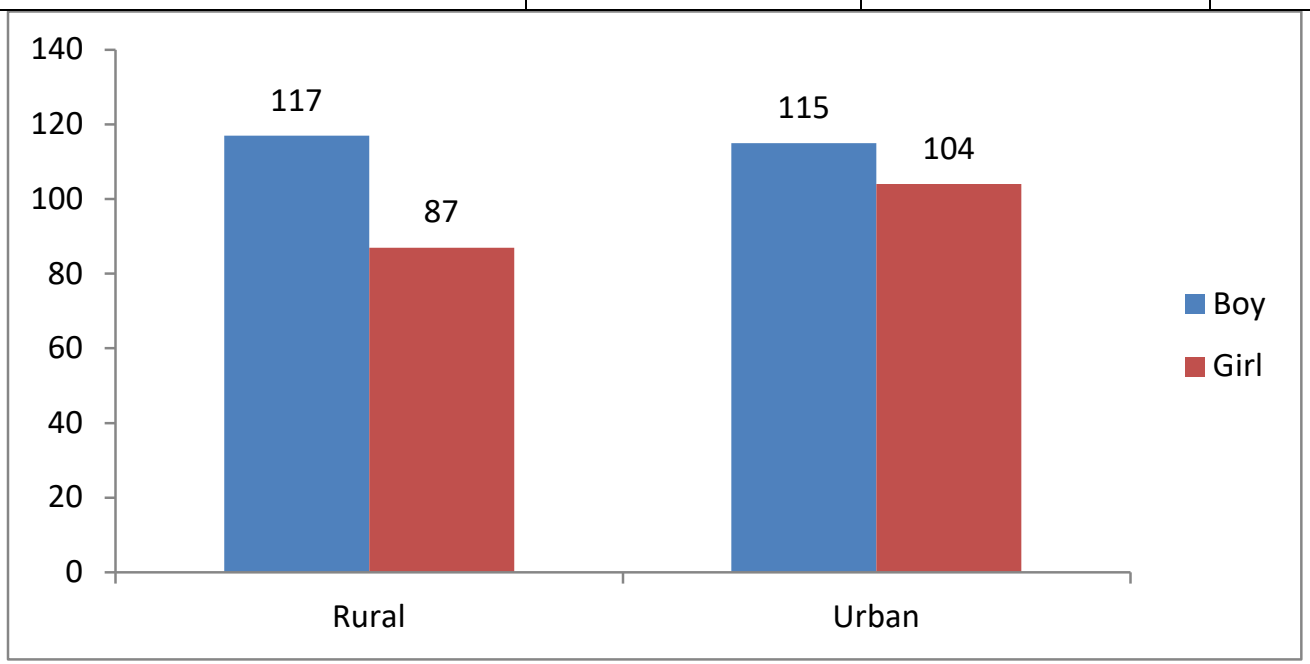

\section{Research Methodology}

Research wants to get the information from the mass and wants to know the present scenario. So, he selected the "Survey Method" for present study.

\section{Tool Construction}

To construct the Spiritual Intelligence Scale, researcher followed the following steps:

Step-1: In-depth study of Spiritual Intelligence

Step-2: Determine the component for Spiritual Intelligence

Step-3: Writing the statements

Step-4: Primary form of Spiritual Intelligence Scale

Step-5: Pre-Piloting

Step-6: Secondary form of Spiritual Intelligence Scale after necessary changes

Step-7: Expert review for Secondary form of Spiritual Intelligence Scale

Step-8: Piloting after necessary changes suggested by Experts review

Step-9: Item Analysis

Step-10: Final Form of Spiritual Intelligence Scale

\section{Data Collection}

Permission of selected schools' principals was asked. After getting the permission rapport was established with the students. Tools were given to students to get response. After giving enough time tools were collected. 
Towards Excellence: An Indexed, Refereed \& Peer Reviewed Journal of Higher Education / Dr.

\section{Veenben Patel \& Mr. Ajay Raval / Page 175-182}

\section{Data Analysis}

Obtain data was entered into Excel Programme of the M.S. Office.

Data was classified as per objectives and Hypotheses with the help of Filter.

$>$ To determine the level $\mathrm{P}_{33}$ and $\mathrm{P}_{67}$ was calculated.

$>$ To check the null-hypotheses, "t'"-test was applied.

Table: B

Level of Spiritual Intelligence

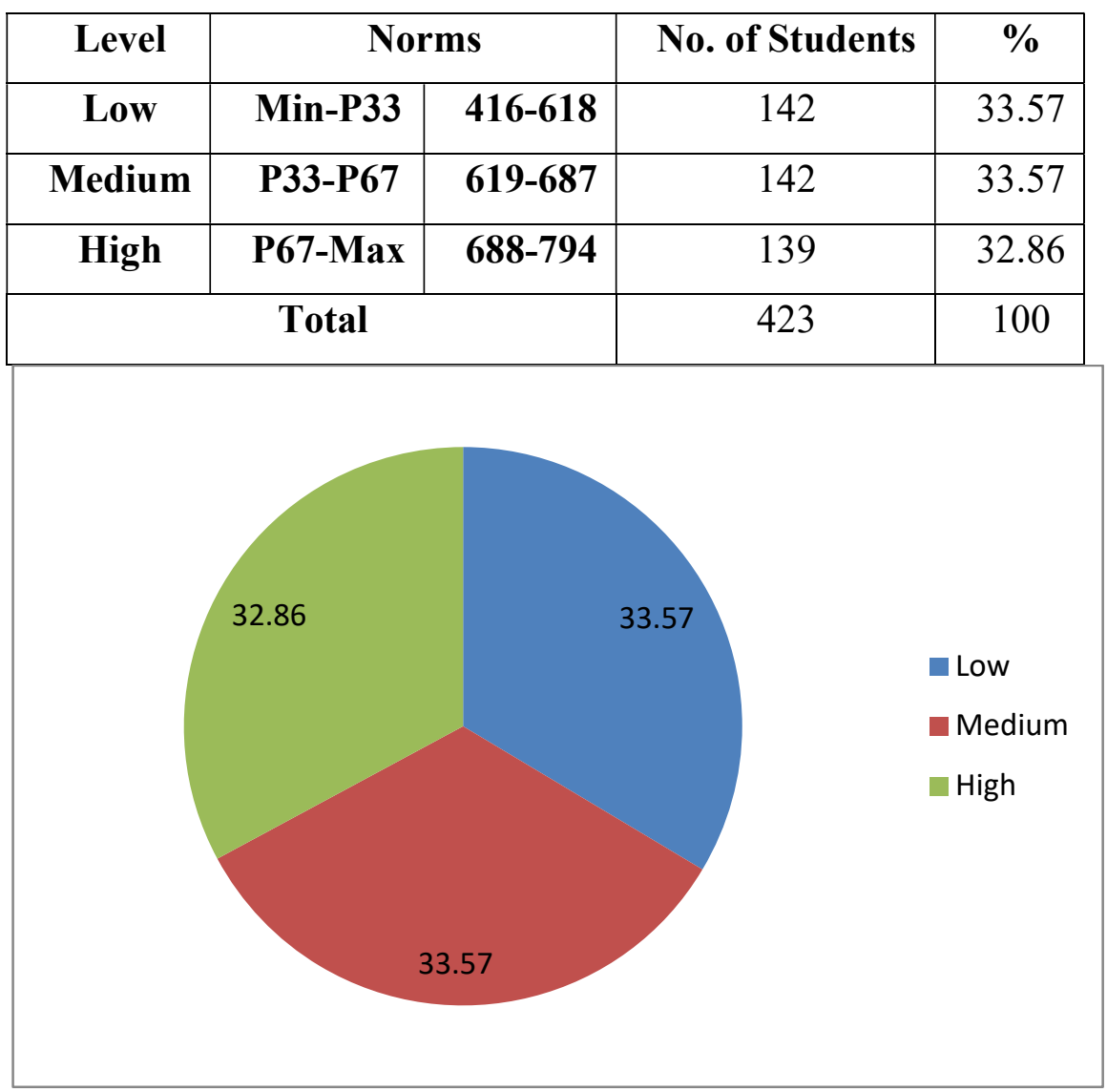

Table: C

Level of Spiritual Intelligence in context of Area

\begin{tabular}{|c|c|c|c|c|c|c|}
\hline \multirow{2}{*}{ Level } & \multicolumn{2}{|c|}{ Norms } & \multicolumn{2}{c|}{ Rural } & \multicolumn{2}{c|}{ Urban } \\
\cline { 4 - 7 } & \multicolumn{2}{|c|}{ No. of Students } & $\%$ & No. of Students & $\%$ \\
\hline Low & Min-P33 & $\mathbf{4 1 6 - 6 1 8}$ & 69 & 33.82 & 73 & 33.33 \\
\hline Medium & P33-P67 & $\mathbf{6 1 9 - 6 8 7}$ & 72 & 35.29 & 70 & 31.96 \\
\hline High & P67-Max & $\mathbf{6 8 8 - 7 9 4}$ & 63 & 30.88 & 76 & 34.70 \\
\hline \multicolumn{3}{|c|}{ Total } & 204 & 100 & 219 & 100 \\
\hline
\end{tabular}




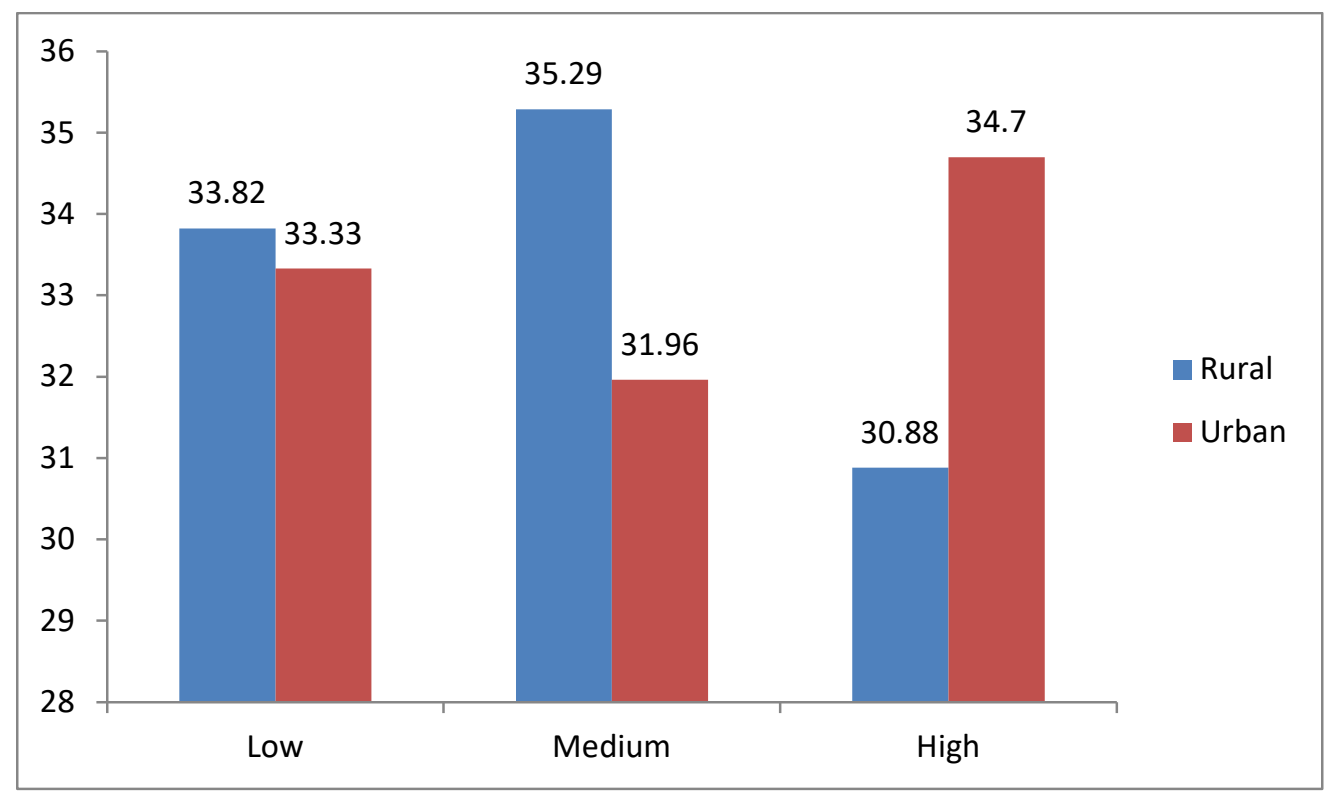

Table: E

Hypotheses Testing

\begin{tabular}{|c|c|c|c|c|c|c|c|}
\hline Ho & Group & N & M & SD & Sed & C.R. & Remarks \\
\hline \multirow{2}{*}{ Ho1 } & Urban & 219 & 647.59 & 75.43 & & & \\
\cline { 2 - 8 } & Rural & 204 & 646.35 & 75.71 & & \multirow{2}{*}{ NS } \\
\hline
\end{tabular}

\section{Findings}

1) According to Level of Spiritual Intelligence 33.57\% Students are in Low Level and Medium Level and 32.86\% Students are in High Level.

2) In Low and Medium Level of Spiritual Intelligence, percentage of rural area students is more than urban area students and in high Level it is vice versa.

3) In matter of Spiritual Intelligence students of rural and urban area are equal.

\section{Conclusion}

Spiritual Intelligence is essential topic to explore. It is more important for Students, Teachers and Educationists. This is humble attempt to research the SI among Higher Secondary Schools. More tryouts should be done for getting support to the result of present study. 
Towards Excellence: An Indexed, Refereed \& Peer Reviewed Journal of Higher Education / Dr.

\section{Veenben Patel \& Mr. Ajay Raval / Page 175-182}

\section{Bibliography}

Safara, Maryam and Bhatia, M.S. (2013), Spiritual Intelligence, Delhi Psychitary Journal, Volume-16, No.2, Page No.412

$>$ Rosernberg, M. (1965), Society and the adolescent self-image, Princeton, NJ: Princeton University Press.

$>$ Agrawal J. C. (1996), Education Research and Introduction, New Delhi:Arya Book Depot.

$>$ Patel, R. S. (2009), Shaixanik Sanshodhana maate Ankadashaastreey paddhatio,(2 ${ }^{\text {nd }}$ Ediction), Ahmedabad, Jay Publication

$>$ Uchat D. A. \& Others, (1985), Sanshodhan aheval nu lekhan shee reete karasho?, Rajakot: Nik Sauko Center, Sahajanand, Saurastra Kala Kendra Soceity

$>$ Desai K. G. \& Desai H. G., (1997), Sanshodhan Paddhatio ane pravidhio, (6 ${ }^{\text {th }}$ Edition), Ahmedabad: University Granth Nirman Board

\section{Dr. Veenaben Patel Mr. Ajay Raval}

